\title{
Evaluating the Properties of Bio-oil Modified Bitumen Derived from Cotton Stalk Waste
}

\author{
Sahib Ullah ${ }^{1, *}$, Syed Bilal Ahmed Zaidi ${ }^{2}$, Akhlaq Aman ${ }^{3}$ \\ $1^{*}$ Research Scholar, Department of Civil Engineering, University of Engineering and Technology Taxila, Pakistan; \\ sahibullah85@gmail.com, +923438865067 \\ 2 Dr. Syed Bilal Ahmed Zaidi, Assistant Professor, Department of Civil Engineering University of Engineering and \\ Technology Taxila, Pakistan; bilal.zaidi@uettaxila.edu.pk, +923225065322 \\ 3 Research Scholar, Department of Civil Engineering, University of Engineering \& Technology Taxila, Pakistan; \\ akhlaqaman13@gmail.com, 923469050047 \\ *Corresponding author Email: sahibullah85@gmail.com
}

\begin{abstract}
Disposal of industrial and agricultural waste is a serious environmental problem across the globe. The environmentally friendly disposal of this Industrial waste by using it in a binder for asphalt mixtures is one of the key focuses of today's research in pavement engineering. The bio oils which are derived from various agricultural wastes has been found to modify or partially substitute the conventional asphalt binder. Effective use of cotton stalk (CS) waste to produced biooil for using in asphalt can help in reducing environmental problems. In this research, the conventional asphalt binder was modified with bio-oil obtained from CS at $5 \%$ and $10 \%$ by weight to determine its effect on the properties of conventional asphalt binder. The Dynamic Shear Rheometer is used along with conventional asphalt binder testing to assess the rheological properties of modified asphalt binders. Results from this study reveals that bio-oil extracted from CS can be used to enhance the low-temperature rheological properties of conventional asphalt binders.
\end{abstract}

Keywords: Agricultural waste, Cotton stalk, Bio-oil, Rheological properties

\section{INTRODUCTION}

Globally cotton stalk (CS) is an important agriculture by-product. Worldwide across 80 countries, more than twelve million hectares of land is cultivated with cotton[1]. China is the biggest producer of cotton in the world, and every year generate cotton stalk of 40 million tons[2]. Usually, this agriculture waste is dumped in landfill which eventually generate environmental pollution. In the rainy season, this waste combine with ground water and made them unsuitable for drinking purposes. A shortage of land is an additional problem associated with the dumping of CS waste. These environmental problems can be diminished by the proper utilization of cotton stalk waste.

Asphalt which is a mixture of aggregates mixed with a form of glue material known as asphalt binder or bitumen. Bitumen is a material which is highly viscoelastic and water-resistant substance. Bitumen is a highly viscoelastic and water-resistant substance with strong adhesive properties obtained from crude oil vacuum distillation and used as a binder to mix mineral fillers in asphalt pavements[3].

Resources of petroleum asphalt is decreases with the passage of time and, results in the diminution of asphalt binder quantity. Also, the implementation of environmental regulations on the boring of new resources reduces the asphalt binder quantity. All these factors reduce the production of asphalt binders which led to a rise in cost and making the asphalt binder expensive. Researchers have turned their attentions to introduce alternative material that can replace partially conventional asphalt binders. In this regard, researchers are investigating materials that would be environmentally friendly, sustainable and cost-effective.

Bio asphalt is one such ground-breaking alternative to conventional asphalt binder, which can be obtained from pig manure[4], urban garden waste [5], grass[6, 7], tea residues[8] and waste coffee fields[9]. Bio-asphalt is an environmentally friendly and renewable material[10] that can be obtained by extraction or thermal chemical 
liq-uefaction from biomass. Bio asphalt is therefore a good alternative to traditional asphalt binder [11].

To obtain bio-oil from biomass, researchers have used various modern techniques. One of the common techniques for use is pyrolysis to alter biomass into solids, liquids and gaseous components by thermal decomposition while omitting oxygen presence. There are different types of pyrolysis processes including fast, slow, catalytic and flash pyrolysis processes [12],but usually, for bio-oil generation, a fast or quick pyrolysis process is used which is the most efficient and effective process. [13, 14].In the quick pyrolysis process, the biomass is first heated to minimize the content of water and heated then in the lack of oxygen at a temperature between 450 and 600[10]. The vapours formed during this process are condensed into bio-oil.

Generally, as a petroleum base binder, bio-oil has similar constituents. Bio-oil components can be categorised into asphaltenes, aromatics, saturates, and polar components. [15]. However, due to the higher content of oxygen, the composition of bio oil on the elemental base varies considerably from the standard petroleum asphalt binder. [16-18].Bio-oil show inhomogeneity and lower $\mathrm{pH}$ as compared to conventional asphalt binder[19]. Bio-oil obtained from various sources has a different impact on asphalt binder performance. Bio-oil extracted from animal waste can enhance asphalt binders' low-temperature performance $[16,20,21]$. Wen et al. suggested that bio oils derived from waste cooking oils can also enhance the performance of asphalt binders at low temperatures[22]. On the other hand, bio-oils produced from wood resources has been found to enhance the stability of asphalt at elevated temperatures while compromising performance at low-temperature[10, 23]. Furthermore, earlier research has concluded that bio oil is more prone to elevated temperatures than conventional asphalt binder. [10, 20].

Mohammad et al. added different percentages of biooil into 64-22, 70-22 and 76-22 performance grading conventional asphalt binder and investigated the lowtemperature crack resistance, high-temperature antirutting performance, anti-fatigue performances, and water sensitivity. The percentages of oil were $20 \%, 25 \%$, $30 \%$ and $50 \%$. The study concluded that the incorporation of bio oil enhances the crack resistance at low temperature, while at high temperature its performance was not stronger as compared to conventional asphalt binder[24].

Peralta et al. incorporated rubber powder in bio asphalt binder at a dosage of $10 \%$ and $15 \%$. After the production of the rubber modified asphalt, the PG of asphalt and chemical composition were investigated through rheological experiments and infrared spectrum. The results showed that bio asphalt and rubber powder have strong compatibility. The addition of $10 \%$ and $15 \%$ rubber powder improved the performance grading of bio asphalt binder up to 58-22 and 64-22 performance grading[25].

Onochie et al. added four percent of nano-silicon and two percent of nano-clay in modified asphalt binder with pig manure. Dynamic shear frequency scanning and the high-temperature viscosity tests were performed. The findings suggested that addition of nano-materials improve the high-temperature performance[26].

Bio-oil was extracted from CS in this study and used as a modifier for conventional asphalt binder, and the properties were analysed to check the effect of bio-oil on conventional asphalt binder. Conventional and DSR tests were performed to assess the effect of CS bio-oil on the characteristics of conventional asphalt binder.

\section{MATERIAL PREPARATION}

\subsection{Cotton stalk}

The source of bio-oil which is known as cotton stalk (CS) were procured from Faisalabad city of Punjab province in Pakistan. The properties of CS are displayed in table 1.

Table 1. Proximate analyses of cotton stalk [27]

\begin{tabular}{cccccc}
\hline Material & $\begin{array}{c}\text { Ash } \\
(\text { Wt. \%) }\end{array}$ & $\begin{array}{c}\text { Moisture } \\
(\text { Wt. \%) }\end{array}$ & $\begin{array}{c}\text { Fixed } \\
\text { carbon } \\
\text { (Wt. \%) }\end{array}$ & $\begin{array}{c}\text { Volatile Low heat } \\
\text { (Wt. \%) }\end{array}$ & $\begin{array}{c}\text { value } \\
\text { (MJ/Kg) }\end{array}$ \\
\hline $\begin{array}{c}\text { Cotton } \\
\text { stalk }\end{array}$ & 6.97 & 7.87 & 15.62 & 69.54 & 15.99 \\
\hline
\end{tabular}

\subsection{Bitumen}

The bitumen used in this study were 60/70 grade penetration. It was procured from Pak-Arab Refinery Limited Company (PARCO), which is a good source for bitumen procurement in Pakistan. Various properties of PARCO bitumen are displayed in Table 2

Table 2. Properties of Conventional Asphalt Binder

\begin{tabular}{lcl}
\hline Physical property & Test Value & Standards \\
\hline $\begin{array}{l}\text { Penetration } \\
\text { Test }\left(0.1 \mathrm{~mm}, 25^{\circ} \mathrm{C}\right)\end{array}$ & 66 & AASHTO T 49-97 \\
$\begin{array}{l}\text { Softening Point } \\
\text { Test }\left({ }^{\circ} \mathrm{C}\right)\end{array}$ & 50 & AASHTO T 53-96 \\
$\begin{array}{l}\text { Ductility } \\
\text { Test }(\mathrm{cm})\left(25^{\circ} \mathrm{C}\right)\end{array}$ & $120+$ & AASHTO T 51-94 \\
\hline
\end{tabular}

\subsection{Bio oil}

The bio oil used in this research is extracted from CS by quick pyrolysis technique, in which CS is heated and the vapours produced are converted into the liquid state through the condensation process. The residual material 
remains at the bottom is known as biomass ash. It is of utmost importance to first sun-dry the CS to reduce the moisture. The Principal properties and components of bio-oil obtained from CS are displayed in Table 3.

\subsection{Bio-oil modified asphalt binder preparation}

Modified asphalt binders were prepared by incorporating $5 \%$ and $10 \%$ of CS bio-oil by weight of conventional asphalt binder. A dose of 0 percent, 5 percent and 10 percent was prepared as trial dosages to examine its effect on conventional asphalt binder. For uniform mixing, a shear mixer machine was used. First the conventional asphalt binder was heated at $120^{\circ} \mathrm{C}$ and then CS bio-oil was added. After this, both traditional asphalt binder and CS bio-oil were blended for 30 minutes through a shear mixture with a speed of 15,00 revolutions per minute (RPM). A hot plate was used to maintain $120^{\circ} \mathrm{C}$ for the specified time. The ID's of asphalt binders and Cotton stalk bio-oil used in this research are displayed in Table 4.

\section{EXPERIMENTAL PROGRAM}

\subsection{Penetration Test}

The test determines the asphalt binder consistency. The test was conducted in compliance with AASHTO T 49-97, under specified conditions for both bio-oil modified and unmodified samples. Penetration of the needle into modified and unmodified samples was measured according to the specified standard conditions. The load of the needle was $100 \mathrm{~g}$ and the duration for loading was 5 seconds. The speed of pull was $50 \mathrm{~mm}$ per minute. Both modified and unmodified samples were put for a period of about 1.5 hours in a water bath at 25 degrees. In terms of its $0.1 \mathrm{~mm}$ units, the penetration of the needle was obtained.

Table 3. Principal properties and components of cotton stalk bio-oil [27]

\begin{tabular}{ll}
\hline Principal Properties & CS Boil Oil \\
\hline $\mathrm{H}_{2} \mathrm{O}($ wt. \%) & 24.45 \\
$\mathrm{H}_{2} \mathrm{O}($ wt. \%) & 17.78 \\
$\mathrm{pH}$ & 3.310 \\
$\mathrm{Viscosity}\left(\mathrm{mm}^{2} / \mathrm{s}\right)$ & 125.1 \\
Density $\left(\mathrm{kg} / \mathrm{m}^{3}\right)$ & 1160 \\
$\mathrm{~S}($ wt. \%) & 0.210 \\
$\mathrm{O}($ wt. \%) & 49.50 \\
$\mathrm{~N}($ wt. \%) & 0.305 \\
\hline
\end{tabular}

Table 4. Asphalt Binders ID's Used in this analysis

\begin{tabular}{lc}
\hline Sampling Type & $\begin{array}{c}\text { Respective } \\
\text { (ID) }\end{array}$ \\
\hline Cotton stalk Bio-oil & CS Bio-oil \\
\hline
\end{tabular}

\begin{tabular}{ll}
\hline Base Asphalt Binder & B1 \\
Asphalt Binder Containing 5\% & B2 \\
Bio-oil & \\
$\begin{array}{l}\text { Asphalt Binder Containing 10\% } \\
\text { Bio-oil }\end{array}$ & B3 \\
\hline
\end{tabular}

\subsection{Softening Point Test}

The test determines the tendency of bitumen to flow at an elevated temperature and is useful in the classification of Bitumen. The test for determining the softening point of both modified and unmodified samples was carried out according to AASHTO T53-96, with the help of Ring and ball apparatus. The rings of brass were filled with bitumen, after cooling to normal condition, $3.5 \mathrm{~g}$ circular shape balls were placed at the top surface of the bitumen filled brass rings. Bitumen filled brass rings were positioned in a clean water bath and the whole assembly was heated up. The heat was applied to the water bath at a uniform rate of a rising of 5 degrees per minute. Finally softening point was obtained by taking the average of the temperatures at which each steel ball touch the plate which is below $25 \mathrm{~mm}$.

\subsection{Ductility Test}

The ductility of bitumen indicates the elongation of bitumen when a tensile full is applied. The test was conducted in accordance with AASHTO T51-94-94. First, the molds were cleaned and then filled with bitumen and finally placed in a ductilitometer. The elongation in both modified and unmodified bitumen samples were observed and measured when the clips were allowed to pull from both sides at specified temperature and speed. The stretching speed and temperature were $50 \mathrm{~mm}$ per minute and 25 degrees centigrade respectively. The distance in $\mathrm{mm}$ covered by the clips before the failure of the sample was noted and is referred to as the ductility value for that sample.

\subsection{Performance Grading Test}

The performance grading test using the Anton Paar Dynamic Shear Rheometer (DSR) was conducted in accordance with AASHTO $\mathrm{T}$ 315. Pavement performance at intermediate and elevated temperatures can be investigated through DSR. [28]. In this study at 25 $\mathrm{mm}$ geometry and $10 \mathrm{~Hz}$ frequency, the performance grading test was carried out and failure temperatures were noted when $\mathrm{G}^{*} / \mathrm{sin} \delta$ dropped below one kilo pascals.

\subsection{Frequency Sweep Test}

Under strain-controlled conditions, the frequency sweep test were performed at six various temperatures $\left(22^{\circ} \mathrm{C}, 34^{\circ} \mathrm{C}, 46^{\circ} \mathrm{C}, 58{ }^{\circ} \mathrm{C}, 70{ }^{\circ} \mathrm{C}\right.$ and $\left.82{ }^{\circ} \mathrm{C}\right)$. The 
diameter of the plate used was $25 \mathrm{~mm}$ for temperatures above 40 degrees with a $1 \mathrm{~mm}$ gap and $8 \mathrm{~mm}$ for temperatures below 40 degrees with a $2 \mathrm{~mm}$ gap. The frequency ranged from one hertz to ten hertz during the test. A strain limit of 0.45 percent and 10 percent was applied to bio oil modified asphalt binder and conventional asphalt binder respectively. Rheological parameters like phase angle, rutting factor and complex shear modulus were investigated.

\subsection{Multiple Stress Creep Recovery (MSCR) Test}

The asphalt binders' elastomeric response is determined by the percentage of recovery and nonrecoverable creep compliance (Jnr) obtained in the test. In accordance with ASTM D74055, the test was conducted using DSR at $64{ }^{\circ} \mathrm{C}$. The constant stress creep was sustained for a period of 1.0 seconds, which was followed by a 9.0 second zero-stress recovery. The range of stress level was from $25 \mathrm{~Pa}$ to $25,600 \mathrm{~Pa}$, and ten cycles were run for each stress level. After the creep and recovery time, the residual strain in the sample was measured in terms of $\mathrm{J}_{\mathrm{nr}}$, through the following equation.

$$
\mathrm{J}_{\mathrm{nr}}=\operatorname{avg}\left\langle\frac{\gamma \mu}{\tau}>\right.
$$

where

$\mathbf{J}_{\mathrm{nr}}=$ The residual strain divided by the stress in a sample (after a period of creep and recovery cycle) (in the $\mathrm{kPa}$ unit, s), $\tau=$ shear stress that is applied for an interval of 1-second. $\gamma \mu=$ represent the permanent strain after an interval of 9 -second. At each temperature and stress level $(0.25 \mathrm{kPa}$ to $3.2 \mathrm{kPa})$ the residual strain was determined.

\section{RESULTS AND DISCUSSION}

\subsection{Penetration, Softening point and ductility tests results}

Figure 1 indicate the effects of bio-oil on the conventional and modified bitumen penetration values. Penetration values basically reflect the asphalt binder's hardening and stiffness at a moderate temperature. A greater value of penetration indicates that the binder has become soft. Figure 1 shows that the penetration value increased by rising the bitumen bio-oil content, which essentially means a decrease in stiffness and an increase in bitumen fluency. When $5 \%$ bio-oil was incorporated (by bitumen mass), penetration significantly increased by $19.5 \%$, while a $27.1 \%$ increase in penetration value was reported by rising the bio-oil dosage to $10 \%$.

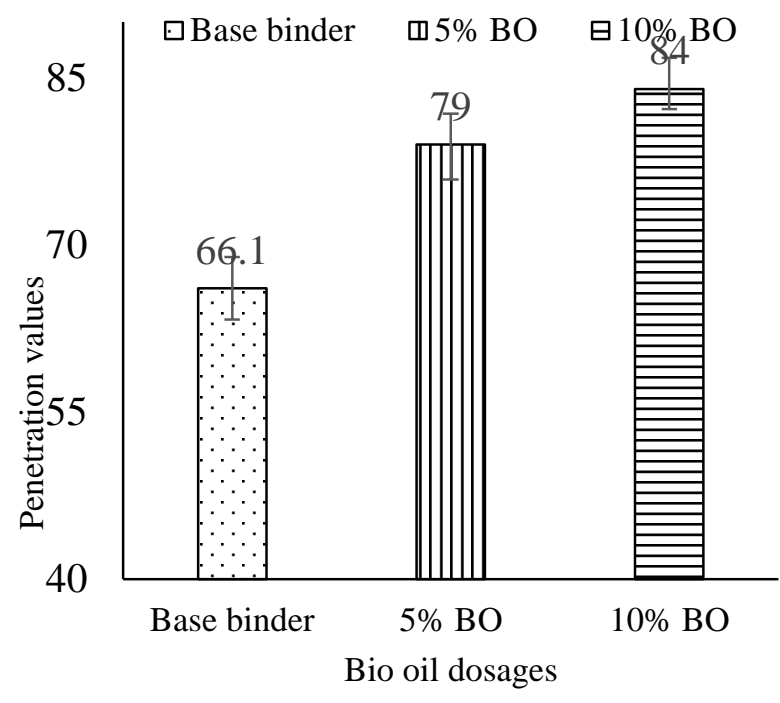

Figure 1. Graphical representation of the penetration values obtained for every sample

The softening point test is typically performed to determine the rough limit between viscoelastic and viscous bitumen behaviour and to assess bitumen resistance to deformation at elevated temperatures. The incorporation of bio-oil (by mass of bitumen) decreased the softening point as shown in figure 2 . When $5 \%$ and $10 \%$ of bio-oil was added a decrease of 1 degree and 2 degrees in the softening point of conventional asphalt binder was observed respectively. This decrease in softening point shows that the incorporation of bio oil extracted from CS softer the conventional asphalt binder.

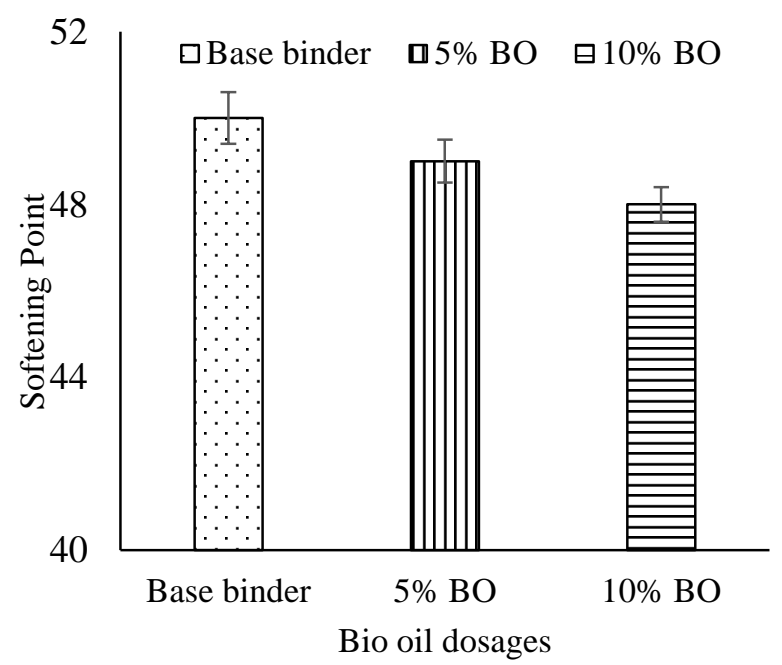

Figure 2. Softening point graphical representation obtained for each sample

The ductility test provides information about each asphalt binder sample's tensile properties. The results obtained are shown in Table 5. The results indicate that the Values of ductility are $120+$ for all samples which show that all the asphalt binders are flexible and will be more resistive to fracture in low-temperature regions. 
Table 2. Ductility Values for Each Binder Sample

\begin{tabular}{ll}
\hline Samples & Ductility Value \\
\hline B1 & $120+$ \\
B2 & $120+$ \\
B3 & $120+$ \\
\hline
\end{tabular}

Generally, low softening point, high penetration values and high ductility values indicate that the addition of bio-oil soft the conventional asphalt binder, and thus the CS bio oil modified asphalt binder would be ideal for use in regions with low temperatures.

\subsection{Temperature Susceptibility}

The penetration index (PI) is use to determine the effect of adding bio oil on temperature susceptibility of the asphalt binder. As demonstrated by Ahinola et al. the temperature susceptibility assessment is determined below using subsequent equations[29].

$$
\text { P.I }=\frac{20-500 \mathrm{~B}}{1+50 \mathrm{~B}}
$$

Where

$$
B=\frac{\log (800)-\log (\text { Penetration at } T)}{\text { Softening Point }-25}
$$

Where $\mathrm{T}$, is the temperature at which the penetration test is conducted $\left(25{ }^{\circ} \mathrm{C}\right)$, Pen at $\mathrm{T}$, Represent the penetration at the proper temperature $\mathrm{T}(0.1 \mathrm{~mm}), \mathrm{SP}=$ indicate softening point of asphalt binder $\left({ }^{\circ} \mathrm{C}\right)$ and Pen at $\mathrm{SP}=$ shows the penetration value at the softening point and is presumed to be $800 \quad(0.1 \mathrm{~mm})[30]$. A greater penetration index value specifies lower sensitivity of asphalt binder to temperature. In addition, most asphalt binders are considered to have penetration values between -2 and +2 . Asphalt binders with penetration values lower than -2 are extremely sensitive to temperature, are brittle at lower temperatures and will crack in regions of cold-weather [31]. The PI values are measured and are within the standard range (from -2 to +2 ) for all the bio-oil percentages. The trend in the graph indicate that with increase of percentage of bio-oil the values of PI increases. It can be used as a paving material as the values are within the defined range of -2 and 2, so it would be less vulnerable in the winter season to low temperature cracking.

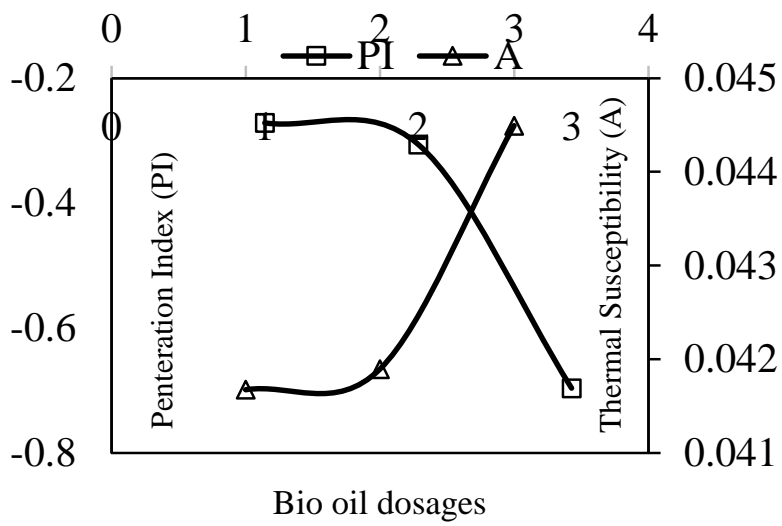

Figure 3. Penetration index of samples of bitumen

\subsection{Dynamic Shear Rheological Properties}

\subsubsection{Performance grade analysis}

In order to determine the rheological high and intermediate temperature properties for both modified and unmodified binder samples, Dynamic Shear Rheometer tests were conducted. Figure 4 indicates the failure temperature against bio oil dosages. Test results show that the incorporation of bio oil to conventional asphalt binder reduces the temperature of failure. With the incorporation of $5 \%$ and $10 \%$ bio oil, the binder failure temperature decreases by $0.94 \%$ and $3.12 \%$, respectively. This decrease in failure temperature indicate that bio-oil addition soft conventional asphalt binder and enhance pavement resistance against fatigue cracking but PG remains the same that is PG 64 for all samples.

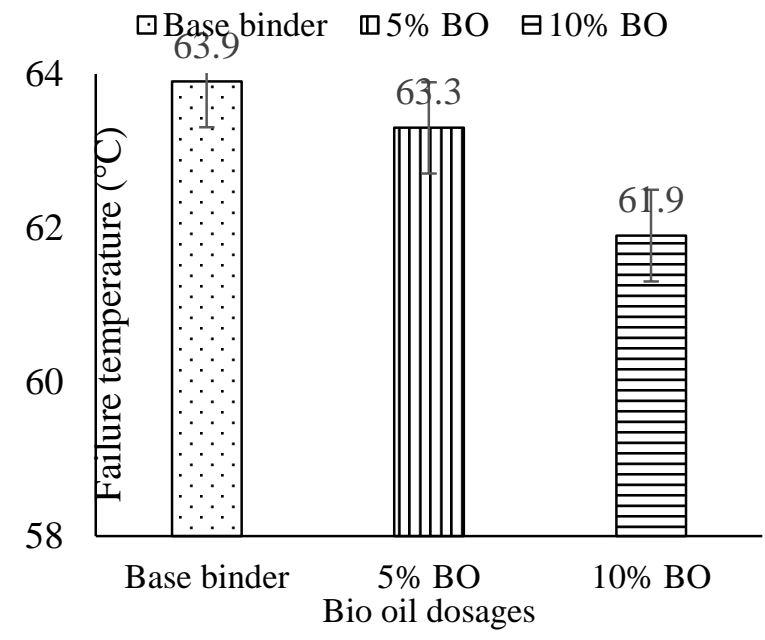

Figure. 4 Graphical representation of failure temperature obtained for each sample 


\subsubsection{Frequency sweep analysis}

A frequency sweep test was performed to determine the influence of time and temperature on all the bitumen samples. It was carried out through a number of temperatures and frequencies. The temperature selected for frequency sweep was $22,34,46,58,70$, and 82 degree Centigrade. The frequencies range was from one hertz to ten hertz. The findings are shown in figure 5 in the form of master curves drawn between phase angle and complex modulus. The master curves were drawn through a sigmoidal function at a reference temperature of $58^{\circ} \mathrm{C}$.

$$
\log |A|=\delta+\frac{\alpha}{1+e^{\beta-\gamma \log \left(f_{r}\right)}}
$$

where $A$ represent the complex modulus, $\delta$ represent the reduced frequency at a reference temperature, $\alpha$ show the variation among min and max complex modulus of asphalt binder and $\beta, \gamma$ indicate the shape parameters of a curve[32]. The master curve of complex modulus ' $\mathrm{G}^{*}$ ' against reduced frequency indicates that at low temperature and high-frequency range the stiffness is decreased when bio-oil is mixed with conventional asphalt binder which means that at high-frequency range master curve of the complex shear modulus shift horizontally towards the right. In conclusion, $10 \% \mathrm{CS}$ bio-oil modified asphalt binder show good fatigue performance as compared to 5\% bio-oil modified asphalt binder and conventional asphalt binder [32]

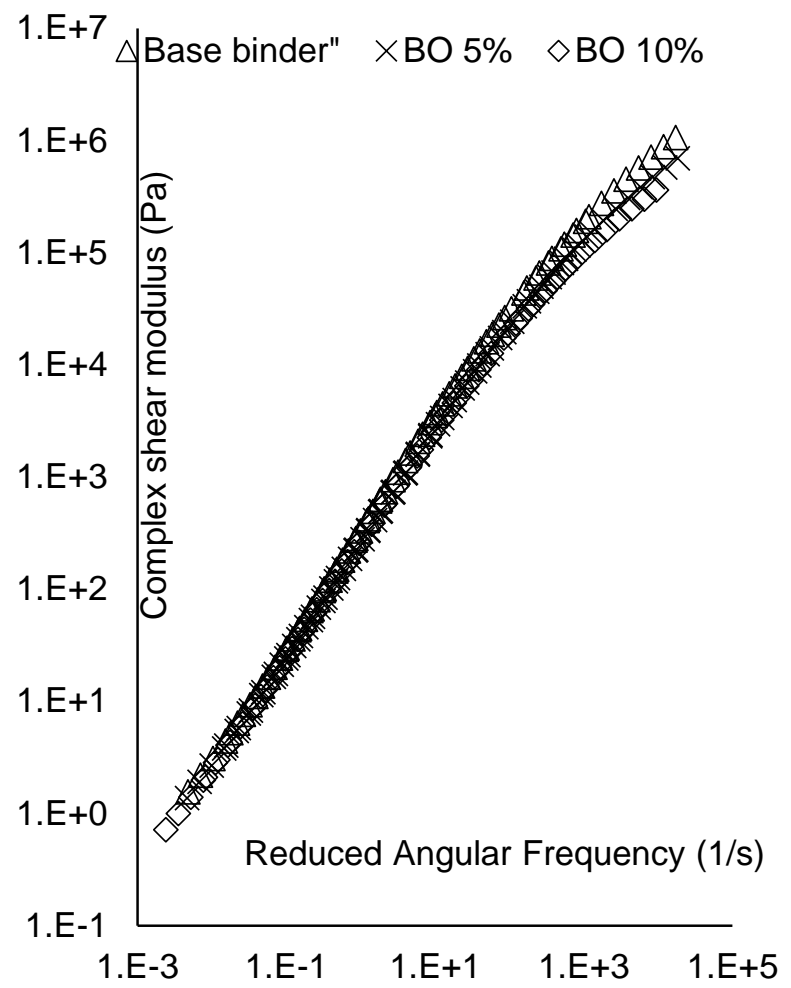

Figure 5. Master Curves drawn among (Reduced Frequency vs. Complex Modulus)
The deterioration of pavement due to heavy traffic loads in the wheel path at high temperature, which is called rutting, is the main and important distress of asphalt pavements. The $\mathrm{G}^{*} / \mathrm{Sin} \delta$ is a factor of rut that indicates a high temperature binder failure. Figure 6 displays the master curve with reduced frequency drawn at the horizontal axis and rut factor drawn at the vertical axis at $58^{\circ} \mathrm{C}$ reference temperature. It can be investigated from Figure 6 that the rut factor decreases in the highfrequency range with the addition of bio oil in the conventional asphalt binder, which basically demonstrates that modified asphalt binder would provide strong anti-cracking efficiency compared to unmodified asphalt binder in the low-temperature range[32].

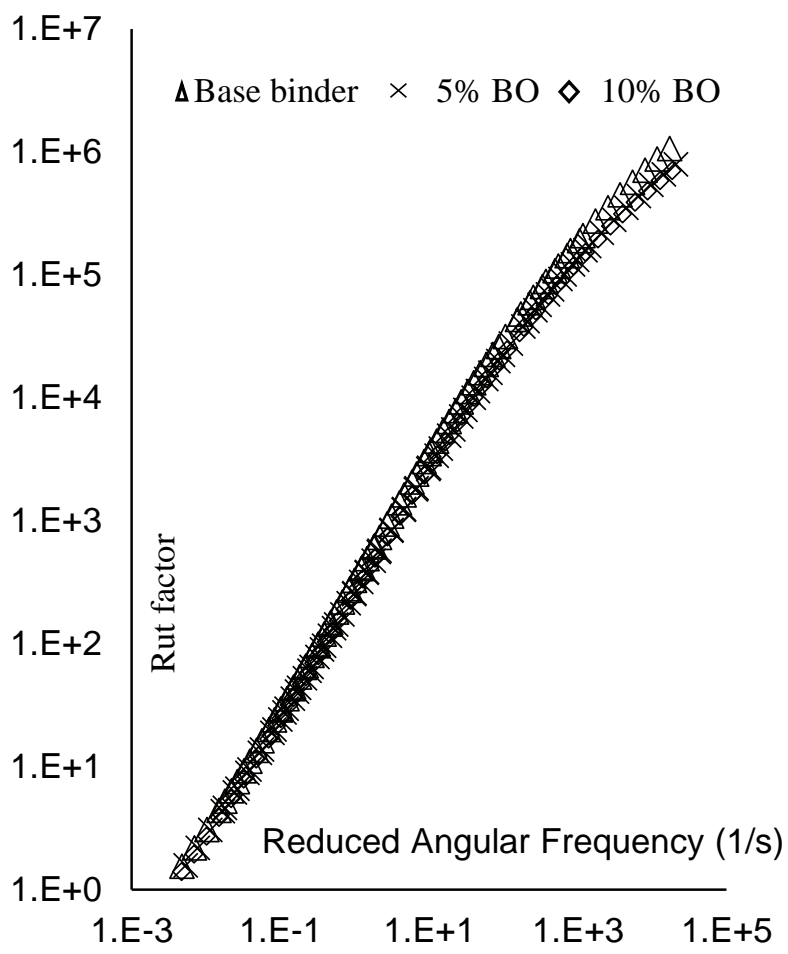

Figure 6. (Rut Factor vs. Reduced Frequency) Master Curves

\subsubsection{Asphalt Binder's Sensitivity to Stress Variations}

To simulate the real pavement force and asphalt deformation through loading mode, which corresponds to the real loading of the pavement, the MSCR test results were analysed. This represents high temperatures performance in the real environment. In addition to being able to sustain continuous deformation at elevated temperatures, every high-quality asphalt binder must be able to properly recover, i.e. remain satisfactorily elastic at a wide temperature range, from different types of stresses placed on it. Figure 7 is plotted at $64^{\circ} \mathrm{C}$ between Percent Recovery as the dependent variable and stress as the independent variable and non-recoverable creep compliance (Jnr). 


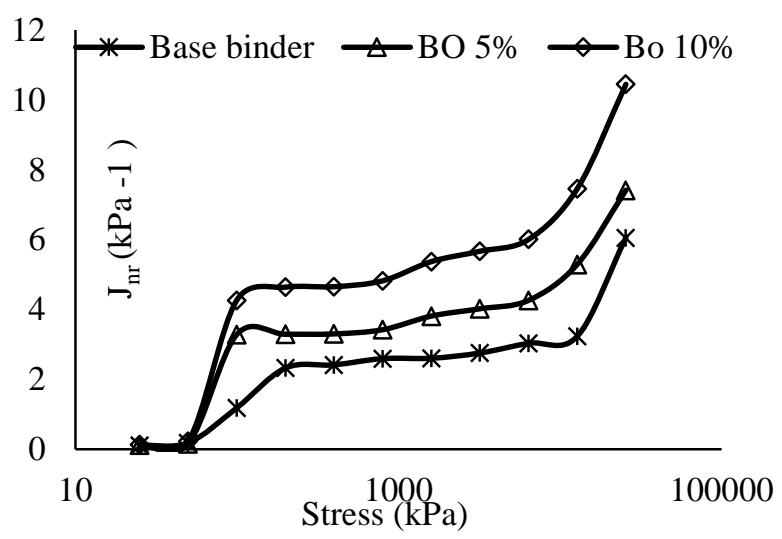

Figure 7. Graphical representation of Stress $(\mathrm{kPa})$ and Jnr $(\mathrm{kPa}-1)$ for each sample

It can be observed that as the stress rises, the value of Jnr also rises while the recovery percentage decreases and the amount depends on the type of binder. Literature shows that Jnr values will be less for stiffer binder than the softer binder. It can be noted from the figure 7 that the Jnr values are getting higher and higher with the inclusion of bio oil in the binder, so it can be concluded from these results that a softer grade binder can be obtained from the stiffer one by modifying the binder with bio oil.

\section{CONCLUSIONS}

Following conclusions have been drawn from the results.

1) In contrast to the base and 5\%,10\% modified asphalt binder gives higher penetration and ductility values and lower softening point values. It means that the CS bio oil addition makes the conventional asphalt binder softer and hence can be used in areas with low temperatures.

2) Asphalt binder performance evaluation using the DSR test reveals that bio-oil addition degrades high temperature performance while enhancing low temperature performance. This is because, in the high-frequency range, stiffness decreases. A major improvement in fatigue resistance is achieved by adding 10 percent bio oil to the conventional asphalt binder.

3) It was found in the DSR test for failure temperature determination that $10 \%$ bio-oil modified asphalt binder fails before 5\% modified asphalt binder and conventional asphalt binder. This means that relative to $5 \%$ modified asphalt binder and conventional asphalt binder, $10 \%$ modified asphalt binder is softer.

Finally, it is concluded that bio-oil obtained from CS enhances the low-temperature performance and is a better option for HMA pavements in low-temperature regions where the primary issue is fatigue cracking.

\section{AUTHORS' CONTRIBUTIONS}

All the testing and major part of analysis has been carried out by sahib ullah, and some part of analysis has been done by Akhlaq Aman and the project has been supervised by Dr Syed Bilal Ahmed Zaidi.

\section{ACKNOWLEDGMENTS}

Author would like to thank staff of the Civil Engineering Department, University of Engineering and Technology Taxila for their support and guidance.

\section{REFERENCES}

[1] S. McIntosh, T. Vancov, J. Palmer, and S. J. B. t. Morris, "Ethanol production from cotton gin trash using optimised dilute acid pretreatment and whole slurry fermentation processes," vol. 173, pp. 42-51, 2014.

[2] S.-k. Du, X. Zhu, H. Wang, D. Zhou, W. Yang, and H. J. B. t. Xu, "High pressure assist-alkali pretreatment of cotton stalk and physiochemical characterization of biomass," vol. 148, pp. 494500, 2013.

[3] F. Pahlavan, M. Mousavi, A. M. Hung, and E. H. J. F. Fini, "Characterization of oxidized asphaltenes and the restorative effect of a biomodifier," vol. 212, pp. 593-604, 2018.

[4] E. H. Fini, D. Oldham, and T. Abu-Lebdeh, "Biomodified rubber: A sustainable alternative for use in asphalt pavements," in ICSDEC 2012. Developing the Frontier of Sustainable Design, Engineering, and Construction, 2013, pp. 489. 499.

[5] D. R. Hill and A. A. Jennings, "Bioasphalt from urban yard waste carbonization: A student study," Ohio Department of Transportation, Research \& Development 2011.

[6] M. A. Raouf, C. R. J. R. M. Williams, and P. Design, "General rheological properties of fractionated switchgrass bio-oil as a pavement material," vol. 11, no. sup1, pp. 325-353, 2010.

[7] J. Peralta, R. C. Williams, H. M. Silva, and A. V. A. Machado, "Recombination of asphalt with bioasphalt: Binder formulation and asphalt mixes application," 2014.

[8] B. B. Uzun, E. Apaydin-Varol, F. Ateş, N. Özbay, and A. E. J. F. Pütün, "Synthetic fuel production from tea waste: characterisation of bio-oil and bio-char," vol. 89, no. 1, pp. 176-184, 2010.

[9] A. Zofka and I. J. T. R. E.-C. Yut, "Investigation of rheology and aging properties of asphalt binder modified with waste coffee grounds," pp. 61-72, 2012.

[10] X. Yang, Z. You, Q. J. I. J. o. P. R. Dai, and Technology, "Performance Evaluation of Asphalt 
Binder Modified by Bio-oil Generated from Waste Wood Resources," vol. 6, no. 4, 2013.

[11] E. H. Fini, I. L. Al-Qadi, Z. You, B. Zada, and J. J. I. J. o. P. E. Mills-Beale, "Partial replacement of asphalt binder with bio-binder: characterisation and modification," vol. 13, no. 6, pp. 515-522, 2012.

[12] H. Goyal, D. Seal, R. J. R. Saxena, and s. e. reviews, "Bio-fuels from thermochemical conversion of renewable resources: a review," vol. 12, no. 2, pp. 504-517, 2008.

[13] T. R. Brown, M. M. Wright, R. C. J. B. Brown, Bioproducts, and Biorefining, "Estimating profitability of two biochar production scenarios: slow pyrolysis vs fast pyrolysis," vol. 5, no. 1, pp. 54-68, 2011.

[14] S. B. Jones et al., "Production of gasoline and diesel from biomass via fast pyrolysis, hydrotreating and hydrocracking: a design case," Pacific Northwest National Lab.(PNNL), Richland, WA (United States)2009.

[15] X. Miao and Q. J. J. o. b. Wu, "High yield bio-oil production from fast pyrolysis by metabolic controlling of Chlorella protothecoides," vol. 110, no. 1, pp. 85-93, 2004.

[16] E. H. Fini et al., "Chemical characterization of biobinder from swine manure: Sustainable modifier for asphalt binder," vol. 23, no. 11, pp. 1506-1513, 2011

[17] M. A. Raouf, M. Metwally, and R. C. Williams, "Development of non-petroleum based binders for use in flexible pavements," 2010.

[18] C. A. Mullen, A. A. J. E. Boateng, and fuels, "Chemical composition of bio-oils produced by fast pyrolysis of two energy crops," vol. 22, no. 3 , pp. 2104-2109, 2008.

[19] A. J. J. o. a. Bridgwater and a. pyrolysis, "Principles and practice of biomass fast pyrolysis processes for liquids," vol. 51, no. 1-2, pp. 3-22, 1999.

[20] A. Onochie, E. Fini, X. Yang, J. Mills-Beale, and Z. You, "Rheological characterization of nanoparticle based bio-modified binder," in Transportation research board 92nd annual meeting, 2013, pp. 125-131.

[21] J. Mills-Beale, Z. You, E. Fini, B. Zada, C. H. Lee, and Y. K. J. J. o. M. i. C. E. Yap, "Aging influence on rheology properties of petroleum-based asphalt modified with biobinder," vol. 26, no. 2, pp. 358366, 2014.
[22] H. Wen, S. Bhusal, and B. J. J. o. M. i. C. E. Wen, "Laboratory evaluation of waste cooking oilbased bioasphalt as an alternative binder for hot mix asphalt," vol. 25, no. 10, pp. 1432-1437, 2013.

[23] R. C. Williams, J. Satrio, M. Rover, R. C. Brown, and S. Teng, "Utilization of fractionated bio oil in asphalt," in 88th annual meeting of the Transportation Research Board, Washington, DC, 2009.

[24] L. N. Mohammad, M. A. Elseifi, S. B. Cooper III, H. Challa, and P. J. T. r. r. Naidoo, "Laboratory evaluation of asphalt mixtures that contain biobinder technologies," vol. 2371, no. 1, pp. 5865, 2013.

[25] J. Peralta, M. A. Raouf, S. Tang, and R. C. Williams, "Bio-renewable asphalt modifiers and asphalt substitutes," in Sustainable bioenergy and bioproducts: Springer, 2012, pp. 89-115.

[26] J. Peralta, R. C. Williams, M. Rover, and H. M. R. D. d. Silva, "Development of a rubber-modified fractionated bio-oil for use as noncrude petroleum binder in flexible pavements," 2012.

[27] J.-l. Zheng, W.-m. Yi, N.-n. J. E. C. Wang, and Management, "Bio-oil production from cotton stalk," vol. 49, no. 6, pp. 1724-1730, 2008

[28] J. P. Zaniewski and M. E. J. A. t. p. Pumphrey, "Evaluation of performance graded asphalt binder equipment and testing protocol," vol. 107, pp 376-384, 2004

[29] O. A. Ehinola, O. A. Falode, and G. J. N. Jonathan, "Softening point and Penetration Index of bitumen from parts of Southwestern Nigeria," vol. 63, no. 9-10, pp. 319-323, 2012.

[30] A. A. Al-Omari, T. S. Khedaywi, M. A. J. I. J. o. P. R. Khasawneh, and Technology, "Laboratory characterization of asphalt binders modified with waste vegetable oil using SuperPave specifications," vol. 11, no. 1, pp. 68-76, 2018.

[31] M. Enieb, A. J. I. J. o. P. R. Diab, and Technology, "Characteristics of asphalt binder and mixture containing nanosilica," vol. 10, no. 2, pp. 148 $157,2017$.

[32] J. Gao, H. Wang, Z. You, M. R. Mohd Hasan, Y. Lei, and M. J. A. S. Irfan, "Rheological behavior and sensitivity of wood-derived bio-oil modified asphalt binders," vol. 8, no. 6, p. 919, 2018. 